\title{
Asylum Seeking and Irregular Migration
}

\author{
Slobodan Djajić
}

Graduate Institute of International and Development Studies

\begin{abstract}
This paper develops a model of optimizing behavior of asylum seekers whose objective is to reach an advanced country. Their personal characteristics and the challenges anticipated along the way determine whether they try to reach the ultimate destination with the aid of human smugglers or by applying for resettlement with the United Nations High Commissioner for Refugees (UNHCR). In the current policy environment, individuals who are relatively young, skilled, wealthy, and have access to credit from the family network are found to have a strong incentive to choose the undocumented migration option.
\end{abstract}

(C) The Authors.

All rights reserved. No part of this paper may be reproduced without the permission of the authors. 


\title{
Asylum Seeking and Irregular Migration
}

\author{
Slobodan Djajic**
}

March 31, 2014

\begin{abstract}
This paper develops a model of optimizing behavior of asylum seekers whose objective is to reach an advanced country. Their personal characteristics and the challenges anticipated along the way determine whether they try to reach the ultimate destination with the aid of human smugglers or by applying for resettlement with the United Nations High Commissioner for Refugees (UNHCR). In the current policy environment, individuals who are relatively young, skilled, wealthy, and have access to credit from the family network are found to have a strong incentive to choose the undocumented migration option.
\end{abstract}

JEL Classification: F22

Key Words: Asylum Seekers, Illegal Immigration

${ }^{*}$ The Graduate Institute of International and Development Studies, 11A Avenue de la Paix, CH-1211 Geneva, Switzerland. Tel: +41-22-908-5934, Fax: +41-22-733-3049, email: slobodan.djajic@graduateinstitute.ch 


\section{Introduction}

Hundreds of thousands of refugees try every year to reach the territory of another country and settle in a more secure environment. In the early 1980s, the number of asylum applications received by the developed countries was in the range of 100,000 to 200,000 per year. It peaked at 850,000 in 1992 , fell back to about 400,000 by 1997 , and then rose again to roughly 600,000 in 2001. For 2009, the industrialized nations received a total of 377,000 asylum requests (IOM (2010)). These large and persistent inflows of asylum seekers over the last two decades have become a major public policy issue, triggering significant changes in asylum policies and practices in the advanced countries. ${ }^{1}$

Individuals fleeing from conflict and oppression obviously aspire to reach one of the prosperous countries where economic opportunities are relatively more accessible. The vast majority of displaced persons, however, are in temporary refugee camps close to the conflict zone, struggling to make ends meet in a neighboring country with an ambiguous residence status, or internally displaced within their home country. Only a small minority ends up with Convention refugee status in an advanced country. ${ }^{2}$

There are two principal ways in which an asylum seeker can reach an advanced country: a) Relatively quickly, but at a high cost and risk, with the aid of human smugglers and without proper documentation or b) by applying for resettlement at a UNHCR refugee facility close to the home country. One would expect that the optimal choice between the two options depends on the asylum seeker's socioeconomic status and other

\footnotetext{
${ }^{1}$ Hatton (2009) provides an excellent survey of the recent trends and a detailed analysis of the impact of policy responses in the host countries and conditions in the source countries on the flow of asylum applications. See also Holzer et al (2000), Vink and Meijerink (2003), Hatton (2004), Thielemann (2004) and Neumayer (2004). Facchini, Lorz and Willmann (2006) study the interaction between asylum policies of two host countries in a citizen-candidate setup, where accepting an asylum seeker in one country generates a crossborder externality in the other.

${ }^{2}$ See Jacobsen (2005) and Hatton (2009). According to the UNHCR (2009), there were 15.2 million refugees worldwide in 2008. Four fifths of the world's refugees are in the developing countries, with the largest number in Pakistan (1.8 million), Syrian Arab Republic (1.1 million), and the Islamic Republic of Iran $(980,000)$. In Sub-Saharan Africa, roughly 70 percent of the refugees reside in camps.
} 
personal characteristics, but also on the asylum and immigration policies of the destination countries. For those trying to reach an advanced country without proper documentation, there are numerous obstacles that stand in the way. They include ever tighter border controls, more onerous visa requirements, bilateral repatriation agreements with the transit and source countries, as well as carrier sanctions which make airlines and other transport companies more vigilant with respect to the documentation requirements of their passengers (see Crisp and Dessalegne (2002)). These obstacles translate into high migration costs and the possibility of failure. For someone fleeing from the conflict in Sri Lanka in 2008-09, for example, the prices for reaching Canada, the UK, and Germany with the aid of human smugglers were $\$ 40,000, \$ 25,000$, and $\$ 20,000$, respectively (see Van Hear 2010, p.15).

This paper considers the problem facing a refugee who has reached the safety of a country of first asylum or a UNHCR facility close to the conflict zone. His objective is to attain a higher level of welfare by moving to an advanced country and gaining access to its labor market. The choice is between using the services of human smugglers and then requesting asylum at the destination or applying for resettlement to an advanced country with the aid of the UNHCR. In the case of failure, the fall-back position is that of remaining in the country of first asylum and/or returning to the country of origin when it is safe to do so. The main objective of the paper is to determine how the policies of the host countries interact with the personal characteristics of the refugees in influencing their behavior. I focus here on the various opportunities and obstacles in relation to resettlement, undocumented migration and refugee status recognition. Identifying and comparing the impact of each obstacle and the role of various personal characteristics in shaping the optimal migration strategy is essential to the formulation of asylum and immigration policies that meet the objectives of the host countries.

The important question of how immigration and asylum policies affect the behavior 
of individuals fleeing oppression and seeking a better life in the wealthier countries is only beginning to attract attention in the theoretical literature. The works of Schaeffer (2009) and Czaika (2009) are the first to consider the choice between remaining in a conflict zone, which generates a certain loss of utility, and attempting to reach a foreign country. ${ }^{3}$ I assume, instead, that asylum seekers have already reached a refugee camp or a country of first asylum, so that their safety is not an issue. They nonetheless strive to improve their welfare further by attempting to gain access to the labor market of an advanced country. In comparison with earlier studies, my focus on this specific phase of the migration process allows us to consider a richer policy environment in the analysis of an asylum seeker's optimization problem.

The remainder of the paper is organized as follows. Section 2 defines the problem facing an asylum seeker. Section 3 compares two principal options available to an individual trying to reach an advanced country: Undocumented migration or applying for resettlement at a refugee facility close to the conflict zone. It is found that in the current policy environment, asylum seekers who are relatively young and have large endowments of human capital and financial assets are likely to choose the undocumented-migration option. The sensitivity of that choice to changes in various policies is examined in Section 4. Section 5 concludes the paper with a summary of the main results.

\footnotetext{
${ }^{3}$ An earlier empirical study by Engel and Ibanez (2007) analyzes the conditions that contribute to flight from home in the case of asylum seekers from Colombia. They find that violence and perceptions of insecurity play an important role in motivating displacement, while pointing out that a family unit's landholdings and social capital can work either way, depending on the nature of the security threat. There are a number of empirical studies that focus on the asylum policies of the host countries. These include Vink and Meijerink (2003), Neumayer (2005), Thielemann (2005), and Hatton (2009). See also the very informative descriptive studies on the behavior of asylum seekers, such as Jacobsen (2005), Grabska (2006), and Jensen (2008).
} 


\section{Two Ways of Getting to the Destination}

The vast majority of asylum seekers don't have relatives in the advanced countries who can host and formally sponsor them. We shall focus only on these cases and assume that there are just two ways to achieve the objective of reaching an advanced country. One is the official asylum-seeking route, which may involve, for example, entering a refugee camp close to the conflict zone, being recognized as a refugee by the UNHCR, and applying for resettlement to an advanced country. It is important to note, however, that only a small proportion of the refugee camp population gets resettled and only a small number of advanced countries take part in the UNHCR resettlement program. ${ }^{4}$ For certain groups of refugees eligible for resettlement programs in the U.S.A., such as the Somali Bantus, Sudanese Southerners, or Mauritanian Fulani, the chances of getting resettled are considerably higher than they are for other groups (see IRIN (2005)). Iraqi refugees have also benefited from generous resettlement programs. Since 2007 the UNHCR Syria has submitted 38,889 cases of Iraqi refugees to potential host countries. Of that number, 17,293 have departed (see IRIN (2010)). These are, nonetheless, small numbers in relation to the millions of people living in hundreds of refugee camps around the world.

Another possibility is to try and enter the destination country directly with the aid of human smugglers, but without the necessary visa and other documentation. As it is practically impossible to obtain an entry visa to an advanced country for the purpose of claiming asylum, legal routes are very few and complex. This has resulted in rapid expansion of human smuggling activities for the purpose of transporting both asylum seekers and economic migrants to their desired destination. ${ }^{5}$ According to Morrison and

\footnotetext{
${ }^{4}$ According to the UNHCR (2010), more than 121,000 refugees were referred for resettlement consideration and 65,548 refugees departed to 26 resettlement countries in 2008 , with the majority going to the United States. Other states that take up significant numbers of candidates for resettlement every year include Australia, Canada and the Scandinavian countries.

${ }^{5}$ There is a growing theoretical literature on migrant smuggling. See, e.g., Friebel and Guriev (2006),
} 
Crosland (2001), the Dutch Immigration Service estimates that 60-70 percent of their asylum applicants have been smuggled into the country. Oxfam (2000) estimates that $90 \%$ of asylum seekers entering Europe did so illegally. If successful in getting to the destination clandestinely, an asylum seeker has the right to apply for asylum and/or try other methods of obtaining a residence permit and eventually permanent residence status. In what follows, we define the two migration options in their simplest forms in order to examine the conditions under which one or the other alternative yields a higher level of discounted utility.

\subsection{Undocumented Migration}

Suppose that human smugglers charge a price $\mathrm{K}$ for attempting to bring a client to an advanced country without proper documentation. The probability of successful migration, $\pi$, is assumed to be exogenously given from the perspective of the migrant. ${ }^{6}$ In case of success, he is able to work in the underground economy and earn $w^{*}(1-\sigma)$ S per unit of time, where $w^{*}(1-\sigma)$ is the underground economy wage per unit of skill, S, possessed by an undocumented worker, a fraction $\sigma$ being the earnings penalty associated with the lack of legal status. ${ }^{7}$ Let us assume, however, that after a certain duration of stay,

Monheim (2008), Tamura (2010, 2013), and Djajic and Vinogradova (2013, 2014).

${ }^{6}$ Success is not guaranteed by merely getting through the border of the host country. In the U.S.A., for example, the expedited removal procedure gives immigration officers the power to order the immediate deportation of people who arrive in the U.S. without proper documents. Between 2004 and 2006, the procedure was expanded to apply to those encountered within 100 miles of any U.S.A. border within the first 14 days after entering the country.

${ }^{7}$ Numerous host countries do not allow asylum seekers to work legally. Other countries do, but only under special circumstances (See Jacobsen (2005) and Landau and Jacobsen (2004)). Even if they do have the right to work while their application for refugee status is being assessed, there are nonetheless numerous obstacles that stand in the way of earning a stable flow of income. As noted by Jacobsen (2005, p.59), employers may not be familiar with the legal rights of asylum seekers and refugees and avoid hiring them to be on the safe side. There are often problems related to language ability or establishing professional qualifications and experience. For these and other reasons earnings of asylum seekers are found to fall far short of those enjoyed by the natives (Jacobsen (2005)). Studies that compare wages of employed undocumented aliens with those of legal immigrants also find a significant gap in favor of the latter. See Rivera-Batiz $(1999,2000)$ and Kossoudji and Cobb-Clark (2002). In some cases skilled, undocumented workers hold unskilled jobs, just to 
$\phi$, in the host country, an undocumented immigrant can finally become a legal resident by obtaining refugee recognition or adjusting status to legal permanent residence (LPR) through some other mechanism. As noted by Gibney and Hansen (2002), even in the case of asylum seekers whose claim was rejected on appeal, very few are actually forced to leave the country. Due to bureaucratic delays, the procedure for attaining LPR status can, however, take many years and even decades. In the case of the U.S.A., for example, in the fiscal year 2004, the waiting period for asylees to obtain the "green card" was at its record high of 18 years (see Wasem (2006, p.19). Adjusting residence status through some other mechanism also requires considerable time. Since 1952, "...there have been at least 16 Acts of Congress that enable aliens in the United States in some type of temporary legal status to adjust to LPR status... e.g., parolees or aliens from specific countries given blanket relief from removal such as temporary protected status (TPS), deferred enforced departure (DED), or extended voluntary departure (EVD)..." (Wasem (2002, p.1). Many of the beneficiaries of such legislation have been in the country for 10, 20 or even 30 years. Similarly, in March 2007, Germany's policymakers reached an agreement to provide residency permits for asylum seekers whose applications were denied in the 1990s but whose deportations have been deferred for some reasons.

The value of $\phi$, determined by immigration policies of the host country, is assumed to depend negatively on both the migrant's skill level, S, and the degree of security risk and oppression, $\Omega$, in his country of origin. The latter strengthens his case for obtaining refugee status, while a higher $\mathrm{S}$ can help improve the prospects of status adjustment to LPR in those host countries that have relatively less restrictive immigration policies with respect to skilled workers. We thus assume that $\phi=\phi(S, \Omega)$, with $\phi_{1}, \phi_{2}<0 .{ }^{8}$

earn a living. The classic example is that of a doctor driving a cab. Even is such cases, however, a worker is likely to be more productive and enjoy higher earnings if he is more skilled, although the wage penalty, $\sigma$ may in reality vary depending on the worker's skills and the type of occupation he has in the underground economy. I assume a constant $\sigma$ to keep the analysis and the exposition tractable.

${ }^{8}$ In his empirical analysis of the refugee recognition rates in Western European countries over the period 1980-1999, Neumeyer (2005) finds strong evidence that the rates are higher for asylum claims from countries 
Status adjustment, if achieved, enables the migrant to earn the official wage $w^{*}$ per unit of skill for the remainder of the planning horizon. Let us assume, in addition, that the initial asset holdings of an individual are given by $\mathrm{A}_{0}$, his age at time of migration is 0 and the planning horizon extends for $\mathrm{T}$ units of time. Under this definition, the younger the individual at the time of migration, the larger is $\mathrm{T}$.

In choosing the undocumented migration option $(\mathrm{U})$, an agent's objective at the time of attempted migration is to maximize the expected lifetime utility

$$
\max _{c_{t}^{*}, c_{t}} \quad E_{0}\left(V^{U}\right)=\pi \int_{0}^{T} u\left(c_{t}^{*}\right) e^{-\delta t} d t+(1-\pi) \int_{0}^{T} u\left(c_{t}\right) e^{-\delta t} d t
$$

where $c_{t}^{*}$ and $c_{t}$ are, respectively, the time $-t$ rates of consumption abroad (in the case of a successful migration attempt) and at home or in the country of first asylum (in the event of a failure). Let us suppose that the migrant's rate of time preference, $\delta$, is constant and that the utility function, $u($.$) , is concave and twice differentiable, with the$ usual properties.

We shall initially assume that credit is available from close family and friends for the purpose of financing migration. As Jacobsen (2005, p.61) points out: "Resettled refugees and asylum-seekers who "make it out" have often been financially assisted by their family, either at home or elsewhere in the diaspora." Thus the budget constraint facing an undocumented migrant requires that, in case of successful arrival at destination,

that are more autocratic, have higher incidence of human rights violations, are involved in external conflicts and have greater incidence of genocide and politicide events. A higher rate of unemployment in the host country is found to be negatively associated with the refugee recognition rate. This suggests that economic factors and the conditions in the labor market in particular, have bearing on status adjustment of an asylum seeker. Moreover, the prospects for adjusting to LPR with the aid of sponsorship of an employer are often better for skilled workers. It is also important to note that there are wide variations across countries with respect to willingness to award asylum seekers in their territory some form of temporary or permanent status. On the basis of data from 1994 to 2002, covering 15 major refugee-receiving countries, Thielemann (2005) finds that the Netherlands, Denmark and Canada are the most generous, with total recognition rates (including those recognized under Geneva Convention and those allowed to remain on the basis of subsidiary protection) of $62.7,61.6$ and 59.8 percent, respectively. 
the discounted savings abroad be equal to the stock of debt, $K-A_{0}$, owed at the time of arrival (or minus the stock of remaining assets if $K<A_{0}$ ).

$$
\left.\int_{0}^{\phi(S, \Omega)}\left[w^{*}(1-\sigma) S-c_{t}^{*}\right]\right) e^{-r t} d t+\int_{\phi(S, \Omega)}^{T}\left(w^{*} S-c_{t}^{*}\right) e^{-r t} d t=K-A_{0},
$$

where $r$ is the rate of interest at which credit is available from the family network, should it be needed to cover migration costs. We assume, for simplicity, that $r$ is equal to the market rate of interest as well as to $\delta .^{9}$

If the migration attempt fails, the asylum seeker is returned to the source country or the country of first asylum, where his labor income is assumed to be $w S$. He uses it to finance his consumption and repay any outstanding debts according to the following budget constraint:

$$
\int_{0}^{T}\left(w S-c_{t}\right) e^{-r t} d t=K-A_{0}
$$

where $w$ is in most cases much smaller than $w^{*}(1-\sigma)$.

After solving this maximization problem, we find that in the case of successful undocumented migration, the asylum seeker's optimal consumption rate abroad is constant at the rate

$$
c^{*}=w^{*} S \frac{\left[(1-\sigma)\left(1-e^{-r \phi(S, \Omega)}\right)+\left(e^{-r \phi(S, \Omega)}-e^{-r T}\right)\right]}{1-e^{-r T}}+\frac{r\left(A_{0}-K\right)}{1-e^{-r T}}
$$

and in the case of a failed attempt and return to the country of origin or the country of first asylum, the consumption rate is also constant, but at a lower rate

$$
c=w S+\frac{r\left(A_{0}-K\right)}{1-e^{-r T}} .
$$

\footnotetext{
${ }^{9}$ One can easily relax this assumption, although it would complicate the analysis slightly and perhaps distract the reader from factors which are specific to the problem of asylum seeking. For an analysis of the optimizing behavior of migrants in a setting where the interest rate differs from the rate of time preference as well as across countries, see Djajić (2010).
} 
Let us assume that the utility function is of the CRRA form $u(x)=x^{1-\theta} / 1-\theta$. With the aid of eq. (1), the expected discounted utility of an asylum seeker who attempts to reach the destination country with the help of a human smuggling organization is then given by

$$
\begin{gathered}
E_{0}\left(V^{U}\right)=\frac{\pi\left(1-e^{-r T}\right)}{r(1-\theta)}\left[w^{*} S \frac{\left[(1-\sigma)\left(1-e^{-r \phi(S, \Omega)}\right)+\left(e^{-r \phi(S, \Omega)}-e^{-r T}\right)\right]}{1-e^{-r T}}+\frac{r\left(A_{0}-K\right)}{1-e^{-r T}}\right]^{1-\theta}+ \\
+\frac{(1-\pi)\left(1-e^{-r T}\right)}{r(1-\theta)}\left[w S+\frac{r\left(A_{0}-K\right)}{1-e^{-r T}}\right]^{1-\theta} .
\end{gathered}
$$

It can be readily seen that $E_{0}\left(V^{U}\right)$ is an increasing function of $\pi, w^{*}, w, S, \Omega, T$, and $A_{0}$ and a decreasing function of $\sigma$ and $K$.

\subsection{Going through a Refugee Camp}

If the asylum seeker enters, instead, a refugee camp in the vicinity of the conflict zone and demands resettlement in a third country, we shall refer to him as having chosen the $\mathrm{R}$ option. In that case, he is obliged to spend $\tau$ years in the camp waiting for the decision. At the end of the procedure, he is either transferred to an advanced country if the application is approved or remains in the home or the first-asylum country if the application is rejected. Let us assume that during the processing period, the refugee is provided with a subsistence level of consumption, $\bar{c}$, by the UNHCR and its implementing partners. This includes food, shelter, health and education services, and other kinds of support. We shall also assume that while waiting in the refugee camp, the individual is not involved in any gainful employment. If he were to exercise his skills and earn an income in the local labor market (other than through work for NGOs or the UNHCR), this would demonstrate ability to sustain himself economically under local conditions and significantly reduce the prospects for resettlement (see Grabska (2006)). He therefore simply consumes at the rate $\bar{c}$ for $\tau$ units of time while waiting 
for the decision on resettlement to be transmitted and refrains from taking part in any employment activities. ${ }^{10}$ Under these conditions, the probability of getting resettled in an advanced country, $\pi^{R}$, is assumed to be an increasing function of both his skill level and the security risks he faces.

$$
\pi^{R}=\pi^{R}(S, \Omega), \pi_{S}^{R}, \pi_{\Omega}^{R}>0
$$

Skill level is important because an asylum seeker with more skill and training is also likely to articulate a stronger case for resettlement. This can play a critical role in leading to a positive decision (see Jansen (2008)). In addition, the higher the value of $\Omega$, the stronger the asylum seeker's claim for refuge and resettlement.

After spending $\tau$ units of time in a refugee camp, a successful applicant is resettled in an advanced country with all the rights of a refugee, including the right to work at the official wage of $w^{*}$ per unit of skill. An unsuccessful applicant remains in the country of first asylum (or gets repatriated to the country of origin) where he earns the wage $w$ per unit of skill. ${ }^{11}$ Within this framework, the problem facing an asylum seeker who chooses the $\mathrm{R}$ option is to maximize

$$
\begin{gathered}
\max _{c_{t}^{R *}, c_{t}^{R}} E_{0}\left(V^{R}\right)=\int_{0}^{\tau} u(\bar{c}) e^{-\delta t} d t+\pi^{R}(S, \Omega) \int_{\tau}^{T} u\left(c_{t}^{R *}\right) e^{-\delta t} d t \\
+\left[1-\pi^{R}(S, \Omega)\right] \int_{\tau}^{T} u\left(c_{t}^{R}\right) e^{-\delta t} d t,
\end{gathered}
$$

where $c_{t}^{R^{*}}$ and $c_{t}^{R}$ are, respectively, the time- $t$ rates of consumption abroad (in case of resettlement) and in the country of first asylum (in the event of denial). Let us assume that getting to a refugee camp, obtaining the required documentation and paying other

\footnotetext{
${ }^{10}$ The principal findings of the paper would not be significantly different if we assumed, instead, that the asylum seeker works in an urban center in the country of first asylum while being registered as a candidate for resettlement with the UNHCR. As we shall see in Section 3, below, his welfare would be slightly increased if he is a highly skilled individual.

${ }^{11}$ It would not make much of a difference if we assumed, instead, that the refugee continues to benefit from the temporary support offered in the refugee camp after the application for resettlement is denied. In reality, support is terminated once the crisis at home is resolved and the camp is shut down.
} 
expenses associated with the resettlement procedure is equivalent to an up-front cost of $K^{R}$. This cost can be covered by initial asset holdings and/or borrowing from the extended family unit. In most cases, $K^{R}$ is only a small fraction of the cost $\mathrm{K}$ of trying to enter an advanced country as an undocumented alien. ${ }^{12}$ If the request for resettlement is approved, his budget constraint is given by

$$
A_{0}-K^{R}+\int_{\tau}^{T}\left(w^{*} S-c_{t}^{R *}\right) e^{-r t} d t=0
$$

Alternatively, if it is denied,

$$
A_{0}-K^{R}+\int_{\tau}^{T}\left(w S-c_{t}^{R}\right) e^{-r t} d t=0
$$

By solving this maximization problem, we find that an asylum seeker's optimal rate of consumption in case of resettlement is constant at

$$
c^{R *}=w^{*} S+\frac{r\left(A_{0}-K^{R}\right)}{e^{-r \tau}-e^{-r T}}
$$

and if the request for resettlement is denied, the rate of consumption is again constant, but at a lower level:

$$
c^{R}=w S+\frac{r\left(A_{0}-K^{R}\right)}{e^{-r \tau}-e^{-r T}},
$$

as $w^{*}>w$. Using these values of $c^{R *}$ and $c^{R}$ in eq. (8), we obtain the expected discounted utility, $E_{0}\left(V^{R}\right)$, of an asylum seeker who chooses the R option at the age of 0.

\footnotetext{
${ }^{12} K^{R}$ involves the cost of getting to the refugee camp, obtaining all the necessary documentation and support of community leaders and other potential witnesses. Numerous reports suggest, however, that a resettlement candidate's chances of success are greater if some form of payment is made to local employees of refugee agencies or community leaders and other individuals whose testimony can play a decisive role in the process. Following commercially-provided courses on "resettlement interview training" and purchasing other relevant information that enhances the prospect of success can also help (see Jansen (2008)). Although the problem of corruption in the refugee resettlement procedure is an important one, I will abstract from this issue and assume that paying more than $K^{R}$ will not affect $\pi^{R}$ nor the exogenously-given amount of time, $\tau$, required by the resettlement procedure.
} 


$$
\begin{gathered}
E_{0}\left(V^{R}\right)=\frac{\bar{c}^{1-\theta}\left(1-e^{-r \tau}\right)}{r(1-\theta)}+\frac{\pi^{R}(S, \Omega)\left(e^{-r \tau}-e^{-r T}\right)}{r(1-\theta)}\left[w^{*} S+\frac{r\left(A_{0}-K^{R}\right)}{e^{-r \tau}-e^{-r T}}\right]^{1-\theta} \\
+\frac{\left[1-\pi^{R}(S, \Omega)\right]\left(e^{-r \tau}-e^{-r T}\right)}{r(1-\theta)}\left[w S+\frac{r\left(A_{0}-K^{R}\right)}{e^{-r \tau}-e^{-r T}}\right]^{1-\theta}
\end{gathered}
$$

It can be readily seen that $E_{0}\left(V^{R}\right)$ is increasing in $\bar{c}, w^{*}, w, S, \Omega, T$, and $A_{0}$, but negatively related to $K^{R}$ and $\tau$ (for realistic values of $\bar{c}$ ).

\section{Comparing the Alternatives}

The manner in which an asylum seeker will attempt to reach an advanced country is determined by the relationship between the expected discounted utilities associated with the two options. These utilities depend, in turn, on the socioeconomic and personal characteristics of the asylum seeker, such as his level of education and skill (S), his age and therefore the length of his planning horizon $(\mathrm{T})$, security risk $(\Omega)$ that he faces in his country of origin or that of first asylum, initial asset holdings $\left(A_{0}\right)$, as well as the variables that are mostly influenced by the policies of the host country. These include the asylum seeker's expected money cost of each of the two options ( $K$ and $\left.K^{R}\right)$, the probability of successful undocumented migration $(\pi)$, the probability of getting resettled abroad by using the $\mathrm{R}$ option $\left(\pi^{R}\right)$, the number of years required for that procedure $(\tau)$, the expected amount of time $(\phi)$ required to legalize residence status when migrating without required documentation, and the earnings penalty $(\sigma)$ that undocumented workers face in the labor market of the host country .

While $K, K^{R}, \pi, \pi^{R}, \tau, \phi$, and $\sigma$ are largely determined by policies of the host country and refugee organizations, the values of these variables may also depend to a significant extent on the personal characteristics of and resources available to an asylum seeker. Having friends abroad (or simply other migrants of the same origin) can effectively reduce $\sigma$ by widening access to employment opportunities of a newcomer (see Munshi 
(2003)). Immigrant networks can also facilitate adjustment of status in the host country and hence lower $\phi$. Information concerning modes of undocumented entry and quality of services provided by human smuggling organizations is more readily available to individuals connected to immigrant networks at the destination (Gathmann, 2008). Such information can reduce $\mathrm{K}$ and increase $\pi$ for any given set of border control measures of the host country.

All these examples illustrate that for any given set of policies and enforcement measures of the host country, the values of $K, K^{R}, \pi, \pi^{R}, \tau, \phi$, and $\sigma$ can be influenced to some extent by an individual's personal characteristics, including those not captured by our model. One could go a step further to argue that the values of these variables can also be affected by an asylum seeker's behavior. The more effort and resources expended in an attempt to influence one of the variables, the greater the likelihood that the effort will pay off. To keep the analysis tractable, it is best to leave the investigation of some of these relationships on the agenda for future research. In what follows, I shall therefore treat all the policy variables and personal characteristics of an asylum seeker as exogenously given and restrict the analysis of an individual's optimizing behavior to the choice of migration strategy and the associated consumption path.

\subsection{Numerical Example}

A comparison of the $\mathrm{U}$ and $\mathrm{R}$ options is most illuminating with the aid of numerical examples. For this purpose, I will make a number of simplifying assumptions with respect to functional forms and try to set parameter values as realistically as possible, bearing in mind that there is very little available evidence on most of the parameters. Let us suppose that $\Omega \in[0,1]$, while $S \in[0.2,1]$, so that potential earnings of an asylum seeker with the highest skill level are five times greater than those of an individual with the lowest skill level. In addition, let us assume that $\phi$, the number of years it takes 
an asylum-seeking, undocumented immigrant to legalize his residence status in the host country is given by $\phi=\phi_{0}[1-\alpha S-(1-\alpha) \Omega]$, where $\phi_{0}$ is a constant, and $\alpha$ and $(1-\alpha)$ are fractions corresponding to the weights of $S$ and $\Omega$ in influencing the process of speeding up the acquisition of permanent residence status in the host country. It is clear that no country publishes a formula stipulating the weight of each factor that determines the number of years it takes an undocumented immigrant to legalize residence status. This is a very complex process where numerous elements play a role, including those not captured by the present model. Values of $\phi_{0}=20$ and $\alpha=0.8$, however, provide in my judgement a fairly good approximation when it comes to legalization of residence status for undocumented aliens from conflict zones who are seeking asylum in the United States over the last couple of decades. ${ }^{13}$

With respect to the probability $\pi^{R}$ of getting resettled abroad when choosing the $\mathrm{R}$ option, I shall assume that $\pi^{R}=\beta S+(1-\beta) \Omega$, where $\beta$ and $(1-\beta)$ are the weights of $S$ and $\Omega$ in determining the probability of receiving a favorable decision. For the benchmark case, I set $\beta=0.2$. The contrast between the assumed magnitudes of $\alpha$ and $\beta$ reflects the fact that $S$ is likely to have a much greater weight in speeding up regularization of residence status for undocumented immigrants in the advanced countries, while security considerations in the country of origin play the key role in influencing decisions on referrals for resettlement. Sensitivity analysis is conducted in the Appendix to determine if any of the principal findings of the paper depend on the choice of parameters that

\footnotetext{
${ }^{13}$ If $\alpha$ is set at 0.8 and $\phi_{0}$ at 20 years, for example, an individual with the average skill level (i.e., $S=0.6$ ), who comes from a country with the average security risk (i.e., $\Omega=0.5$ ), will need $\phi=20[1-.48-.10]=8.4$ years to legalize residence status in the host country. This is arguably a realistic prediction for such an asylum seeker who enters the U.S. without proper documentation. Having, instead, a skill level of $S=1$ would cut the legalization time to 5 years for these same parameter values. For a country like Sweden, where the majority of asylum seekers who arrived spontaneously at the border in the 1990s managed to legalize their residence status within 5 years, a value of $\phi_{0}$ in the range between 5 and 10 years would be more appropriate. We examine the implications of choosing alternative values of $\phi_{0}$ in the range of 5 to 20 years in Section 4.2 below. If data were available on the level of skill or education of each asylum seeker, the country of origin, and the number of years needed by each of them to legalize residence status in the host country, one would be able to estimate $\phi_{0}$ and $\alpha$. Unfortunately, such data are not available.
} 
determine the values of $\phi$ and $\pi^{R}$ for a given individual. As shown there, the model's qualitative predictions are quite robust with respect to the choice of these parameters. ${ }^{14}$

I measure time in years and set $\tau=3$, as it typically takes about two years to go through the process of refugee status determination (RSD), ask for resettlement, have a standard case file prepared and submitted to a particular resettlement country by the UNHCR, and wait for the approval letter to arrive from a foreign embassy with the approximate date of the interview. If all goes well, this is followed by a medical check-up and departure for the host country about one year after the interview, making $\tau=3$ years a realistic value. I normalize $w$ to unity and set $w^{*}=10$ on the assumption that the real wage in the host country is ten times greater than that of the source country. ${ }^{15}$ To reflect the low marketability of skills in the host country for an individual lacking legal status, I set $\sigma=0.5 .{ }^{16}$ Let us assume that $K=5$ years of source country income or $1 / 2$ of annual disposable earnings in the host country for a documented worker with the highest skill level. As the cost of undocumented migration is in the range of $\$ 20,000-\$ 50,000$ for long-haul migrants, this is arguably a realistic value. I set $K^{R}=0.5$ to reflect the significantly lower cost of seeking resettlement through a refugee-camp. Finally, I assume that the probability of successful undocumented migration on the route in question is at $\pi=0.7$, that the individual has access to credit from the family network at $r=\delta=0.05$

\footnotetext{
${ }^{14}$ What can overturn some of the findings is if $\beta$, the weight attached by the authorities to an an individual's skill level is very large, so that the decisions on resettlement applications are primarily influenced by $S$. This, however, is precisely what the resettlement programs try to avoid, focussing instead on the risks that a refugee faces either in the refugee camp or in the country of origin.

${ }^{15}$ Clemens et al (2009) provide estimates of real wages for observably identical workers in the USA and in 42 (mostly developing) countries. In half of these countries, the ratio of a worker's real wage in the US is at least four times higher, going up to about 15 for Nigeria and Yemen.

${ }^{16}$ North and Houstoun (1976, p.S-11) find the average hourly wage received by undocumented workers in the USD was $37 \%$ lower than the average wage received by all workers in the same industry. Rivera-Batiz (1999) finds the gap to be over $20 \%$ for both male and female workers, when controlling for other personal characteristics. A gap of similar magnitude is found to separate the earnings of documented and undocumented workers on the basis of a data set examined by Kossoudji and Cobb-Clark (2002). All of these studies pertain to the USA and cover mostly low-skilled illegal aliens from Mexico. Undocumented foreign workers with skills are likely to face a larger penalty associated with undocumented status as they face the additional hurdle of having their skills recognized and appropriately rewarded by the employers.
} 


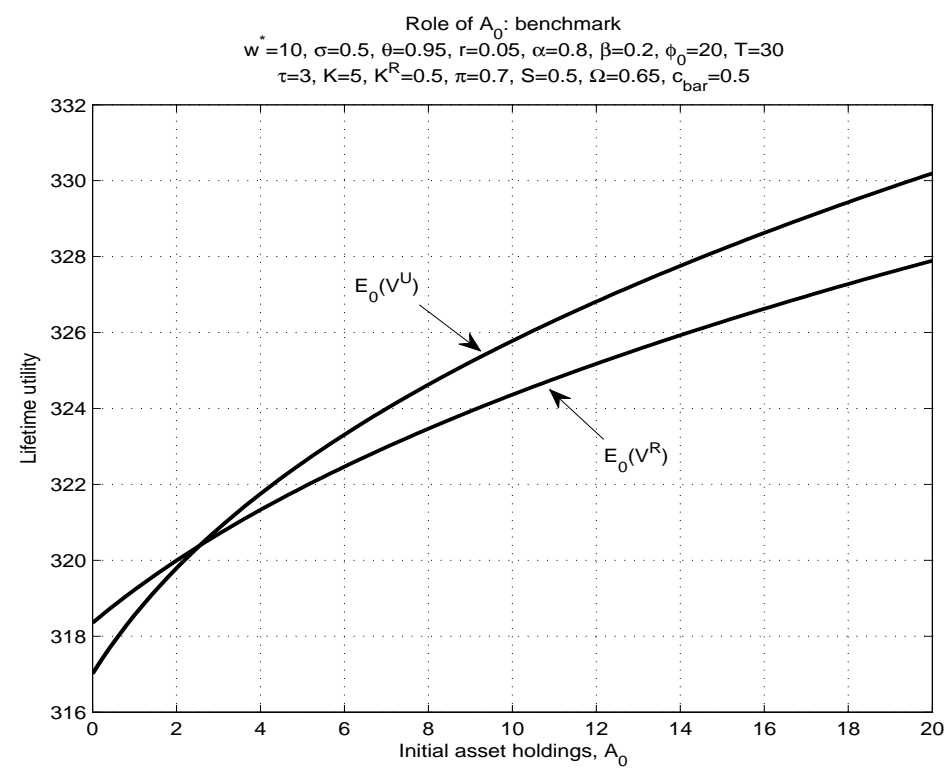

Figure 1: Role of initial asset holdings.

and that the degree of concavity of the utility function $\theta=0.95 .{ }^{17}$ The individual whose behavior is analyzed in the benchmark case is assumed to have the skill level of $S=0.5$, comes from a conflict zone with the insecurity level of $\Omega=0.65$, is of middle age with a time horizon of $T=30$ years, and has no initial asset holdings so that $A_{0}=0$.

\subsection{Role of Initial Asset Holdings}

Figure 1 illustrates the relationship between an individual's initial asset holdings and the discounted utilities associated with the $\mathrm{U}$ and $\mathrm{R}$ options when all other parameters of the model are held at their benchmark levels. Both $E_{0}\left(V^{U}\right)$ and $E_{0}\left(V^{R}\right)$ are obviously increasing functions of $A_{0}$. The $\mathrm{U}$ option, however, is the more risky one in the sense

\footnotetext{
${ }^{17}$ Most estimates of the degree of concavity of the utility function, $\theta$, tend to be in the range from 0.5 to 1.5 (see, e.g., Epstein and Zin (1991), Hansen and Singleton (1982), Keane and Wolpin (2001), Vissing-Jorgensen (2002), Favero (2005), and Kirdar (2010)). Values of $\theta$ in the range between 0.9 and 1.0, however, tend to generate the most realistic patterns of saving behavior of migrants (see Djajić (2010)).
} 
that if the very costly attempt to reach the destination as an undocumented alien ends in a failure, it can leave the migrant significantly poorer (and even heavily indebted, in relation to earnings, if $K$ is much larger than $A_{0}$ ). The $\mathrm{R}$ option is less risky in that a failure to obtain a positive decision on resettlement does not result in as large a drop in the expected time profile of lifetime consumption. Because of this difference, if $E_{0}\left(V^{U}\right)$ is initially equal to $E_{0}\left(V^{R}\right)$, as at the point of intersection in Figure 1, the marginal utility of an extra unit of wealth is higher for an agent choosing $U$ than it is for the one choosing $\mathrm{R}$. This is reflected in the slopes of the two schedules and implies that, if an asylum seeker is initially indifferent between $\mathrm{U}$ and $\mathrm{R}$, an extra unit of wealth will tip the balance in favor of $\mathrm{U}$. We thus have

Proposition 1. Larger initial asset holdings increase the attractiveness of $U$ relative to $R$.

\subsection{Role of $\Omega$}

A higher $\Omega$ raises the utility levels associated with both migration options. For $\mathrm{U}$, it increases the expected lifetime earnings by accelerating the acquisition of legal status in the event of successful undocumented migration. For R, it increases the probability of getting resettled. The latter has a much stronger impact on welfare in comparison with a mere acceleration of the legalization procedure of an agent choosing the $\mathrm{U}$ option. This is reflected in the slopes of $E_{0}\left(V^{U}\right)$ and $E_{0}\left(V^{R}\right)$ schedules in Figure 2. A higher level of security risk and oppression in the country of origin therefore makes the $\mathrm{R}$ option relatively more attractive if all other parameters of the model are held at their benchmark levels.

The slopes of the two schedules obviously depend on the assumed values of $\alpha$ and $\beta$, as well as those of the other parameters. It is therefore essential to determine how 


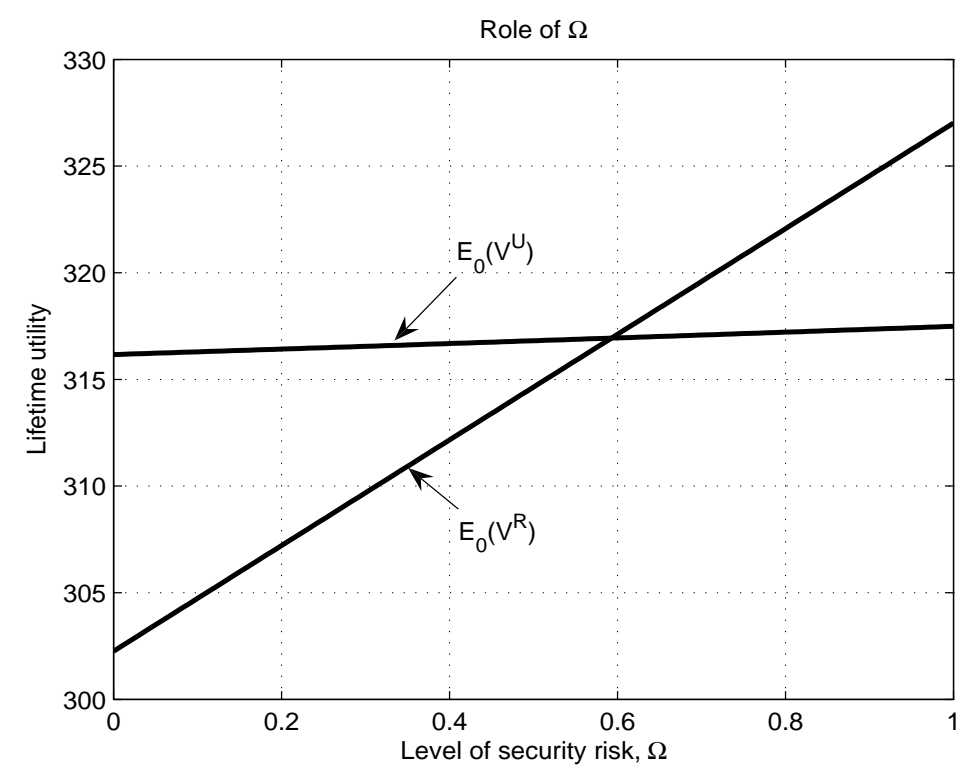

Figure 2: Role of security risk.

sensitive this result is with respect to the choice of parameter values. I examine in Appendix A.1 if the above result can be reversed for any realistic combinations of $\alpha$ and $\beta$ and conclude that this is not the case. Calculations are performed for all values of $S \in[0.2,1]$ and the associated value of $\Omega$ such that $E_{0}\left(V^{U}\right)=E_{0}\left(V^{R}\right)$, as at the point of intersection between the two schedules in Figure 2. It is only for highly unrealistic values of $\beta$ and $\alpha$ (i.e., $\beta>0.8$ in combination with a small $\alpha$ ) that the slope of $E_{0}\left(V^{U}\right)$ can possibly exceed that of $E_{0}\left(V^{R}\right)$ in equilibrium. A value of $\beta>0.8$, however, requires that the criteria for resettlement attach at least a 4 times greater weight to an asylum seeker's $\mathrm{S}$ rather than $\Omega$, which is clearly not the case. ${ }^{18}$

Proposition 2. For realistic values of the model's parameters, a higher degree of security risk and oppression at home makes the $R$ option relatively more attractive to asylum seekers.

\footnotetext{
${ }^{18}$ In Canada, for example, an individual's skill level is not even taken into account when processing unsponsored applications for refugee status (see, e.g., DeVoretz, Pivnenko and Beiser (2004)).
} 


\subsection{Role of Skills}

A higher level of skills increases the utility of the $\mathrm{U}$ option relative to that of $\mathrm{R}$. This is illustrated in Figure 3, where the $E_{0}\left(V^{U}\right)$ schedule is seen to be steeper than the $E_{0}\left(V^{R}\right)$ locus. This is partly due to the fact that the marginal utility of an extra unit of wealth

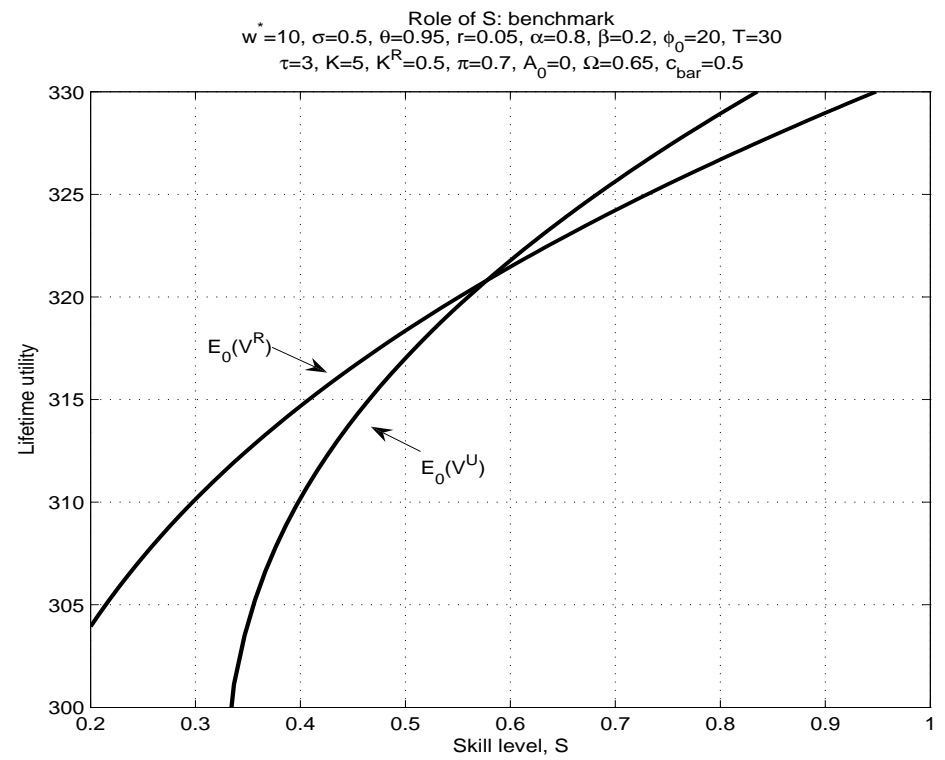

Figure 3: Role of skills.

(including human capital in this instance) is higher under the $\mathrm{U}$ option, as explained in Subsection 3.2. Also playing a role is the assumption that a higher S does not generate extra income in the refugee camp under the $\mathrm{R}$ option, but it does so over the entire planning horizon under the $\mathrm{U}$ option. As explained in Appendix A.2, the slope of the $E_{0}\left(V^{U}\right)$ schedule is greater than that of the $E_{0}\left(V^{R}\right)$ schedule at the point of intersection, not only for the benchmark case, but for all realistic values of the model's parameters. We thus have

Proposition 3. A higher skill level of an asylum seeker makes $U$ more attractive in relation to $R$. 
There is very little data available on the skill composition of asylum seekers. The only empirical studies on this issue that I am aware of, Bevelander (2009) and Bevelander and Pendakur (2009), find evidence that is supportive of Proposition 3. On the basis of Swedish data, they find that refugees who sought asylum at the border and who subsequently obtained a residence permit are, on average, more educated and have higher employment rates than both resettled refugees and family-reunification immigrants, controlling for their country of origin and other personal characteristics.

\subsection{Role of $\mathrm{w}^{*}$}

Figure 4 plots the two expected utilities as functions of the wage paid per unit of skill to legal residents of the host country. At the point of intersection, it shows the $E_{0}\left(V^{U}\right)$ schedule to be steeper than $E_{0}\left(V^{R}\right)$ for the benchmark case. The difference in the slopes

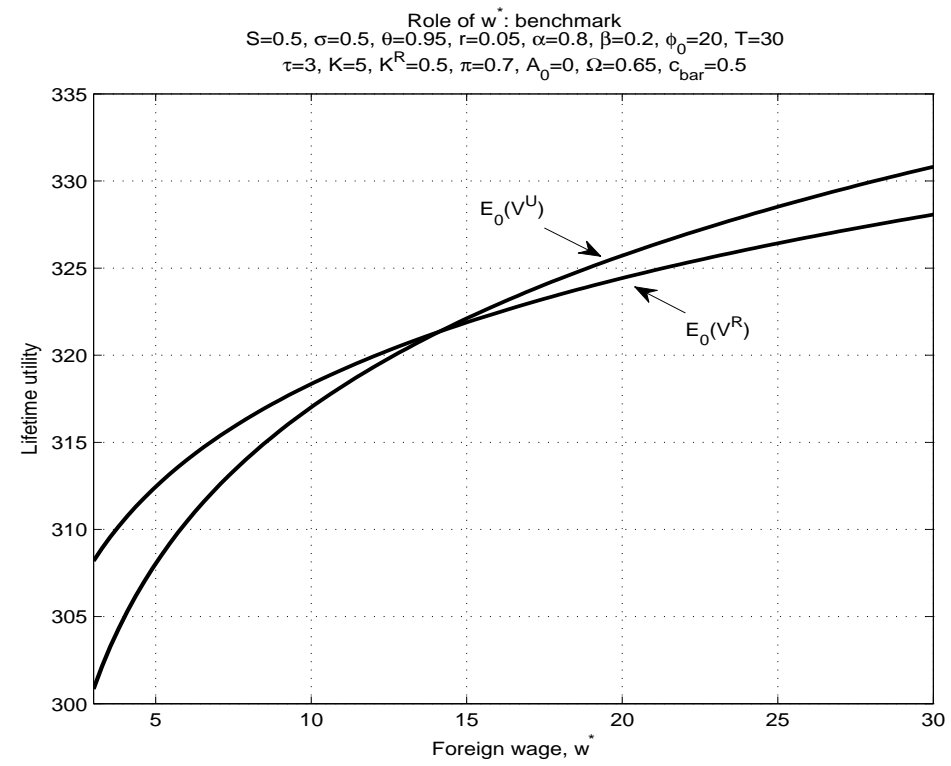

Figure 4: Role of foreign wage.

in equilibrium can be explained, in part, by the fact that a successful undocumented 
migrant gets to benefit from a higher $w^{*}$ over a longer period of time than does a resettled asylum seeker who spends $\tau$ years in a refugee camp. There are, however, two other important elements: First, since we have assumed that undocumented migration is much more costly, in equilibrium $\pi>\pi^{R}$, so that $\mathrm{U}$ faces a higher probability of benefiting from an increase in $w^{*}$ and, second, values it more than $\mathrm{R}$ does because of his higher marginal utility of wealth and income when $E_{0}\left(V^{U}\right)=E_{0}\left(V^{R}\right)$. As explained in Appendix A.3, this result holds even if the values of $\tau, \sigma$, and $\phi_{0}$ are varied as much as realistically possible to increase the slope of $E_{0}\left(V^{R}\right)$ relative to that of $E_{0}\left(V^{U}\right)$. We thus have

Proposition 4. An increase in the wage of the host country makes $U$ more attractive in relation to $R$.

\section{Changes in other Key Parameters}

As most of the remaining exogenous variables, such as $\pi, K, K^{R}, \tau, \sigma$, and $\phi_{0}$ affect only $E_{0}\left(V^{U}\right)$ or $E_{0}\left(V^{R}\right)$, it is obvious as to which direction they influence the choice between the two options. Less obvious is the quantitative impact of each variable in the context of our model. To address this issue, I analyze below the sensitivity of the choice between $\mathrm{U}$ and $\mathrm{R}$ to changes in each of the remaining parameters. As in the previous section, the analysis is conducted with the aid of numerical simulations. For each of the following figures, the thick schedule traces the combinations of $S$ and $A_{0}$ such that an asylum seeker is indifferent between the two options, holding other parameters at their benchmark values: $\alpha=0.8, \beta=0.2, \tau=3$ years, $w^{*}=10, \sigma=0.5, K=5, K^{R}=0.5$, $\pi=0.7, r=\delta=0.05, \theta=0.95, \Omega=0.65, \phi_{0}=20$ years, and $T=30$ years. The schedule is negatively sloped because, as explained in Section 3, both an increase in $S$ and an increase in $A_{0}$ make $\mathrm{U}$ more attractive relative to $\mathrm{R}$. A higher $S$ must therefore 
be accompanied by a lower $A_{0}$ to maintain equality between $E_{0}\left(V^{U}\right)$ and $E_{0}\left(V^{R}\right)$. The remaining thin schedules in each figure trace the combinations of $S$ and $A_{0}$ such that $E_{0}\left(V^{U}\right)=E_{0}\left(V^{R}\right)$ for other specific values of the exogenous variable in question. For an individual with a combination of $\mathrm{S}$ and $A_{0}$ that is above and to the right of a given schedule, U generates a higher expected welfare in relation to R. Conversely, for any combination of $\mathrm{S}$ and $A_{0}$ below and to the left of the schedule, $\mathrm{R}$ is preferred over $\mathrm{U}$.

\subsection{Border Controls}

Figure 5 illustrates the impact of variations in border controls and other policy measures that raise the cost, $\mathrm{K}$, of an attempted undocumented entry into the host country. As $\mathrm{K}$ rises, the $\mathrm{U}$ option becomes less attractive. Individuals with skill levels and asset holdings that made them marginally in favor of the $\mathrm{U}$ option are induced by a higher $\mathrm{K}$ to switch from $\mathrm{U}$ to $\mathrm{R}$. This is shown in Figure 5, where the skill-asset threshold

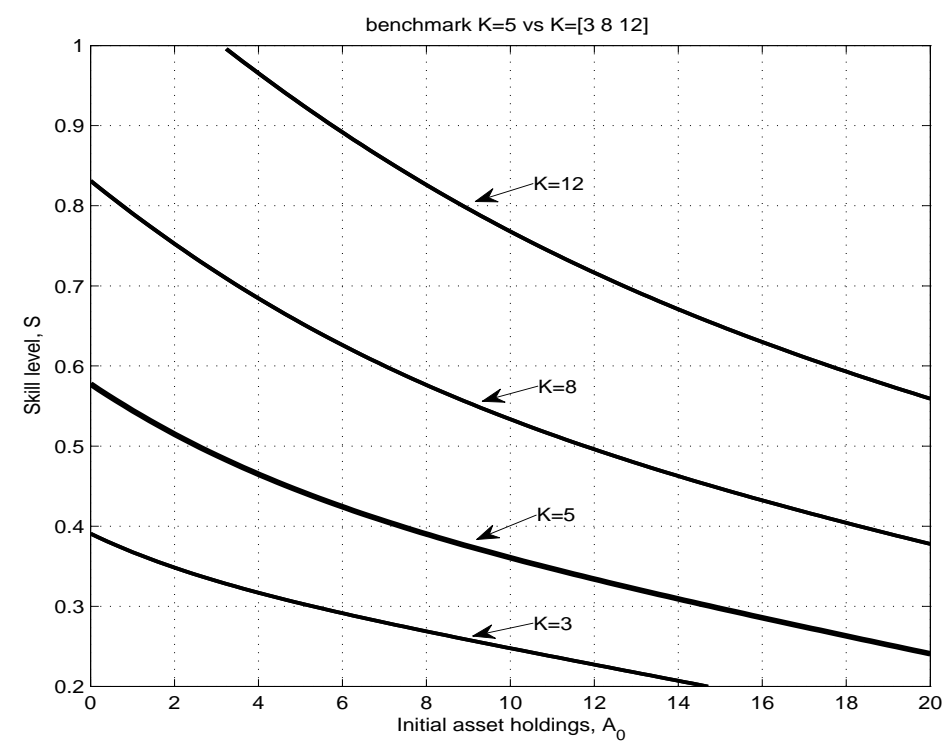

Figure 5: Role of $K$. 
shifts up as the cost of undocumented migration is increased from 5 to 8 or $12 .{ }^{19}$ When migration costs are very high, only those with "high" levels of skills and initial asset holdings find it attractive to pursue the undocumented migration option and bear the risk of failure. As just a tiny proportion of refugees have substantial amounts of assets and skills, the high migration costs that are currently quoted effectively deter the vast majority of them from choosing U. By contrast, if $K$ is as low as 1.25 (i.e., $1 / 8$ of a high-skilled, documented worker's annual earnings in the host country), it can be shown that for the benchmark values of other parameters, the $\mathrm{U}$ option is preferred over the $\mathrm{R}$ option by all individuals with $A_{0}>0$. Thus Figure 5 illustrates very clearly that tough border controls and the costs they generate for undocumented migrants are an effective selection mechanism that promotes positive selection of asylum seekers both in terms of their skills and wealth.

Figure 6 shows the implications of variations in the probability of successful undocumented migration. A fairly high $\pi$ of around 0.8 is sufficient to make the $\mathrm{U}$ option optimal for all individuals with non-negative assets and $S>.38$, when other parameters are at their benchmark values. It is important to emphasize here that we assume credit to be available from the family network for the purpose of covering the cost of migration. As we shall see below, the results are quite different when credit is not available. Note, however, that even with the availability of credit, once $\pi$ falls below 0.6 , it is only the very wealthy and/or highly skilled that will find U attractive. Tightening of border restrictions so as to reduce $\pi$, can therefore be expected not only to reduce the inflows of asylum seekers, but to significantly alter the socioeconomic characteristics of those who are undeterred, as we have already seen in the case of an increase in $K{ }^{20}$

\footnotetext{
${ }^{19}$ Note that $K=5$ corresponds to one half of annual disposable earnings in the host country of a documented worker with $S=1$. With the cost of undocumented migration in the range of 20,000-50,000 US Dollars for long-haul migrants, $K=5,8$ or 12 correspond to empirically relevant values.

${ }^{20}$ Although I am not aware of any evidence on the relationship between restrictiveness of border control measures and the average skill and wealth endowments of those filing asylum applications in the advanced countries, there is strong evidence on the inverse relationship between the number of asylum applications and
} 


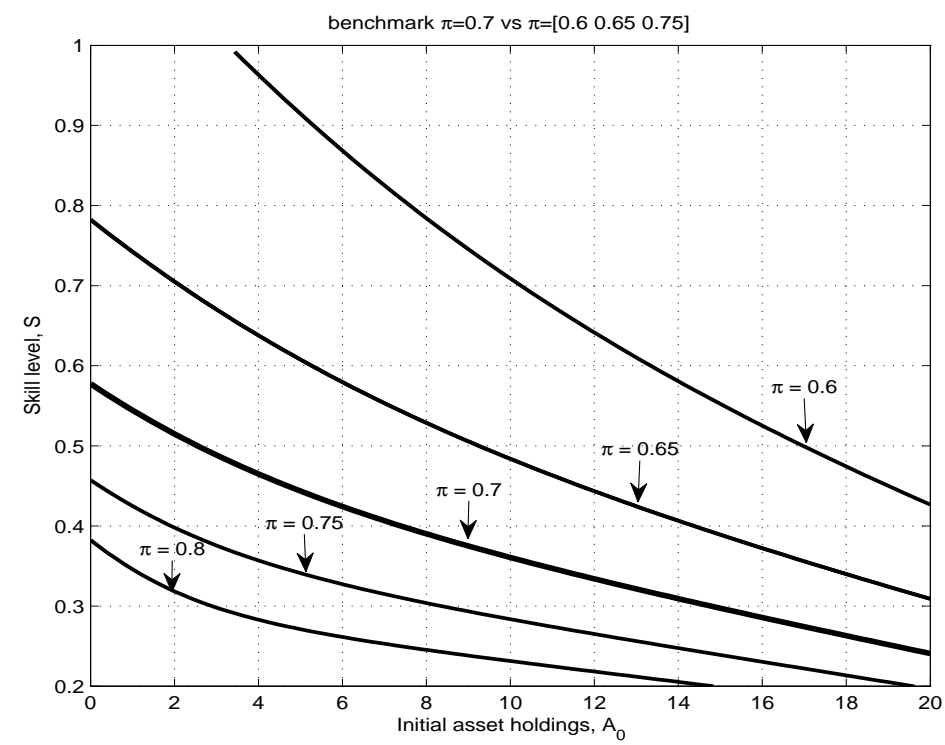

Figure 6: Role of $\pi$.

\subsection{Refugee Recognition and Status Adjustment}

The implications of changes in the expected pace of status adjustment for successful undocumented immigrants are shown in Figure 7. The quicker the pace (i.e., smaller $\phi_{0}$ ), the more attractive is U. It is interesting to note that for someone with a long planning horizon, such as 30 years in our benchmark case, extended delays in legalizing residence status are not a very powerful deterrent when it comes to undocumented migration.

For example, an individual described by point $\mathrm{X}$ in Figure 7 , with no initial asset holdings and $\mathrm{S}=0.672$, is found to be indifferent between the $\mathrm{U}$ and $\mathrm{R}$ options even if it takes a successful U migrant $\phi=\phi_{0}[1-(0.8)(0.672)-(0.2)(0.65)]=9.972$ years (when $\left.\phi_{0}=30\right)$ to become a permanent resident in the host country.

Restrictions on employment of unauthorized persons, as captured in our model by

policy restrictiveness, broadly defined to include a number of policy indicators (see, e.g., Vink and Meijerink (2003), Hatton (2004), and Thielemann (2004)). For 19 major host countries, Hatton (2009) measures the deterrence effect of restricting access to the territory on the flow of asylum applications and finds a strong negative impact. 


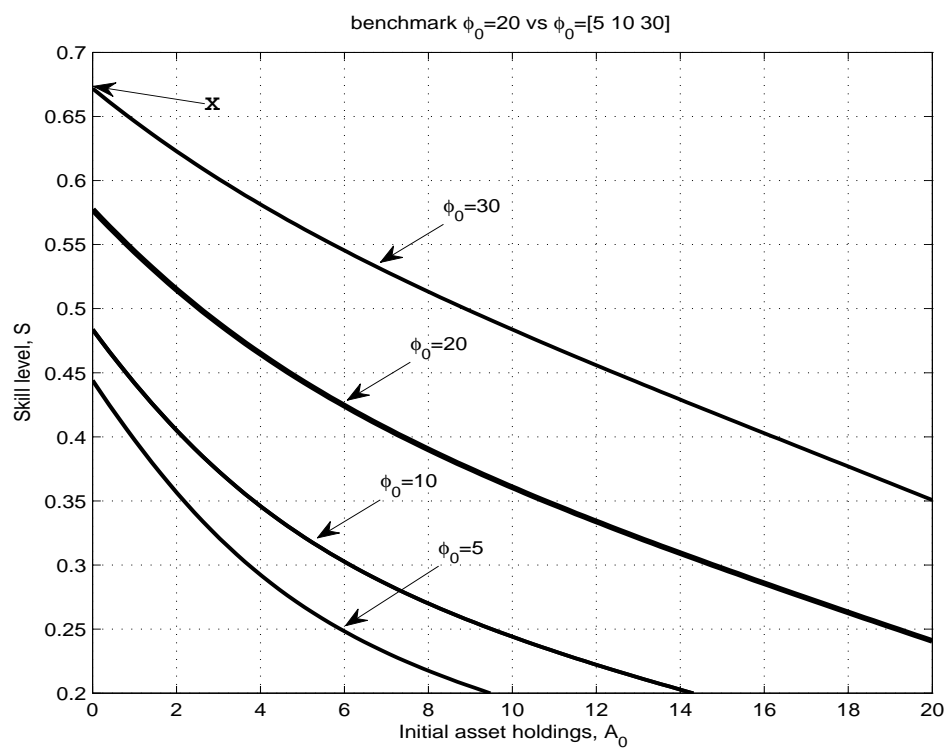

Figure 7: Role of $\phi_{0}$.

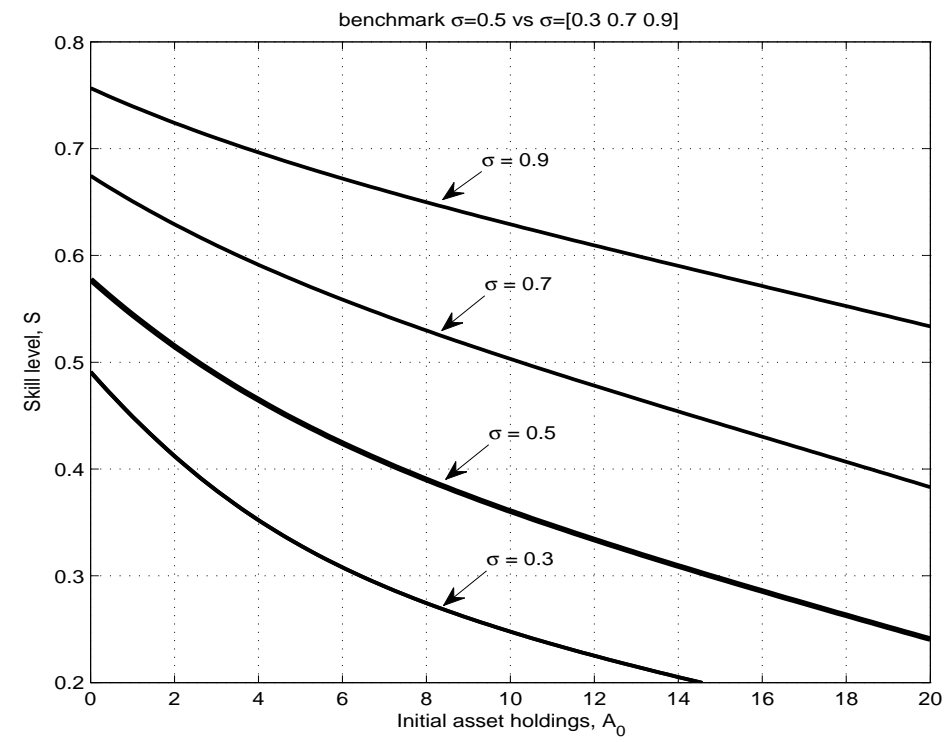

Figure 8: Role of $\sigma$. 
the earnings penalty, $\sigma$, are also a relatively weak instrument in deterring asylum seekers from choosing the $\mathrm{U}$ option. This can be seen in Figure 8, where for a penalty as large as 90 percent, which is far beyond any value observed in the advanced countries, the $\mathrm{U}$ option is still preferred over $\mathrm{R}$ for anyone with $S>0.757$, assuming his initial asset holdings are nil. These results are consistent with Hatton's (2009, p.F209) finding that policies aimed at diminishing the socioeconomic conditions of asylum seekers have a weak deterrent effect on the flow of asylum claims.

\subsection{Conditions in the Refugee Camp}

Let us consider next the parameters that affect only the $\mathrm{R}$ option. A larger daily subsistence and support ration, $\bar{c}$, provided by the refugee agencies in the camp, is shown in Figure 9 to make the $\mathrm{R}$ option relatively more attractive. An increase in the ration from the benchmark level of 0.5 to a level of 1 , which corresponds in magnitude to the sourcecountry earnings of an individual with $S=1$, makes a significant difference. As may be seen in the figure, for those with $A_{0}=0$, it is the skill level of $S=0.756$ rather than 0.577 that represents the threshold value of $S$ such that an asylum seeker is indifferent between $\mathrm{U}$ and $\mathrm{R}$. This suggests that significant improvements in refugee-camp conditions or the treatment of refugees in the country of first asylum, can play an important role in reducing the relative attractiveness of $\mathrm{U}$.

By contrast, variations in the pecuniary cost of the $\mathrm{R}$ option, as represented by changes in $K^{R}$, do not have a major impact on the attractiveness of $\mathrm{U}$ relative to $\mathrm{R}$. It can be shown that a doubling of $K^{R}$ from 0.5 to 1.0 has only a small effect on the threshold value of $S$ such that an asylum seeker with $A_{0}=0$ is indifferent between $\mathrm{U}$ and R. It lowers it from 0.577 to 0.55 . The reason for this lack of sensitivity is that realistic values of $K^{R}$ are rather small, even in relation to source country earnings, allowing $K^{R}$ to play only a minor role. 


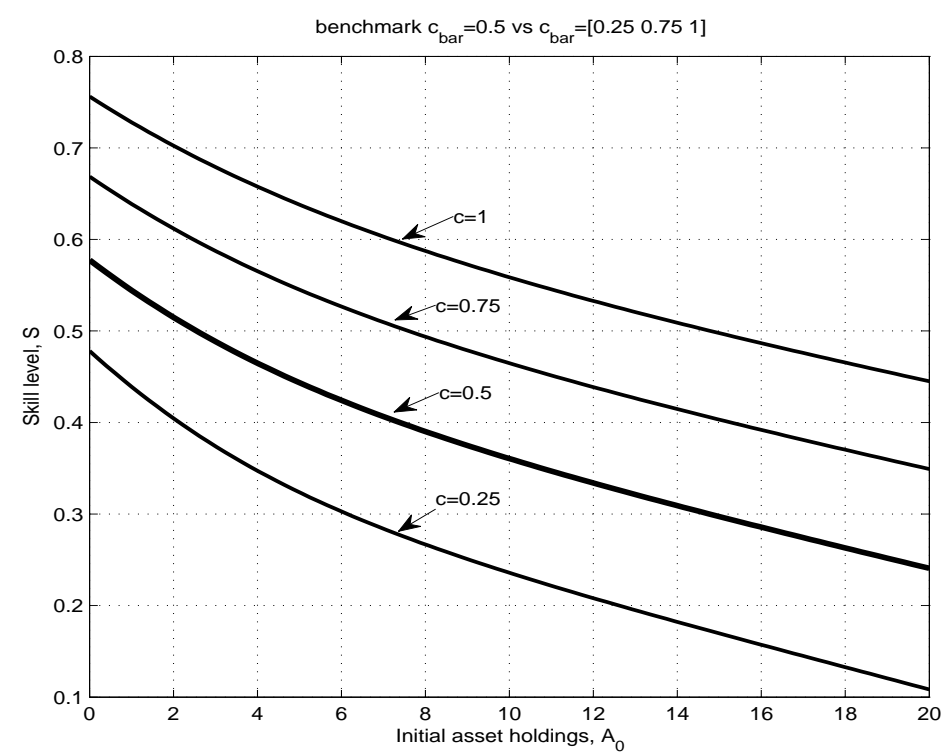

Figure 9: Role of $\bar{c}$.

The effects of changes in $\tau$, the number of years that an asylum seeker can expect to spend in a refugee camp waiting for a resettlement decision are more powerful. A cut in the waiting period from 3 to 2 years can be shown to increase the threshold level of skills that makes an asylum seeker with $A_{0}=0$ indifferent between choosing $\mathrm{U}$ or $\mathrm{R}$ from 0.577 when $\tau=3$ to 0.739 when $\tau=2$.

\subsection{Comparing the Effects of Policy Measures}

While the preceding figures are informative in revealing how the various policies influence the choice between $\mathrm{U}$ and $\mathrm{R}$ for asylum seekers with different personal characteristics, one can go a step further to compare the relative impact of one measure against another. Since our calibrations are only loosely tied to the evidence, due to lack of data, the analysis below is merely intended to illustrate the policy trade-offs and provide some qualitative insights on the relative impact of alternative measures in influencing the 
behavior of asylum seekers.

If we take, for example, the equilibrium in Figure 1, which shows $E_{0}\left(V^{R}\right)=E_{0}\left(V^{U}\right)$ for an individual with $A_{0}=2.55$ (i.e., roughly $1 / 4$ of a year's earnings in the host country for a documented individual with the highest skill level) and other parameters corresponding to the benchmark case, it can be computed that for a one-percent decline in the probability of successful migration (from $\pi=0.7$ to $\pi=0.693$ ) it would require the earnings penalty to fall by approximately 6.6 percent from $\sigma=0.5$ to $\sigma=0.467$ in order to keep this asylum seeker indifferent between $\mathrm{U}$ and R. Similarly, a one-percent decline in $\pi$ is equivalent in terms of its effectiveness in deterring undocumented migration to a 9 percent increase in the expected duration of the waiting period for the legalization of residence status in the host country. It is equivalent, as well, to a 5 percent increase in $\mathrm{K}$, the monetary cost of migration.

We have also seen in Section 4.3 that improved conditions in the refugee camp serve as a deterrent to undocumented migration of asylum seekers. In the present context, a 10 percent increase in the subsistence ration, $\bar{c}$, or a 7.33 percent decline in the waiting period, $\tau$, are both equivalent in terms of the impact on the relative utilities of $\mathrm{U}$ and $\mathrm{R}$ to a one percent decline in $\pi$. In sum, the quantitative impact of variations in $\pi$ on the choice of strategy is very strong in relation to that of other instruments, as suggested by our earlier discussion of the results presented in Figures 5-9. The quantitative impact of a change in $K$ is ranked second, followed by that of a change in $\sigma, \tau, \phi_{0}$, and $\bar{c}$.

\subsection{Asylum Seeker's Time Horizon}

The analysis so far pertains to an asylum seeker with a 30 year time horizon. Younger (older) individuals will have a longer (shorter) time horizon. One important implication of facing a larger $\mathrm{T}$ is that investment in costly undocumented migration, which offers a higher probability of getting to the final destination, becomes more attractive because its 
cost can be spread and benefits enjoyed over a longer period of time. That attractiveness is obviously stronger the higher the skill level of the asylum seeker. Thus, in Figure 10, for an individual with a relatively low level of initial asset holdings, a higher $\mathrm{T}$ lowers the threshold value of $\mathrm{S}$ that makes him indifferent between the $\mathrm{R}$ and $\mathrm{U}$ options.

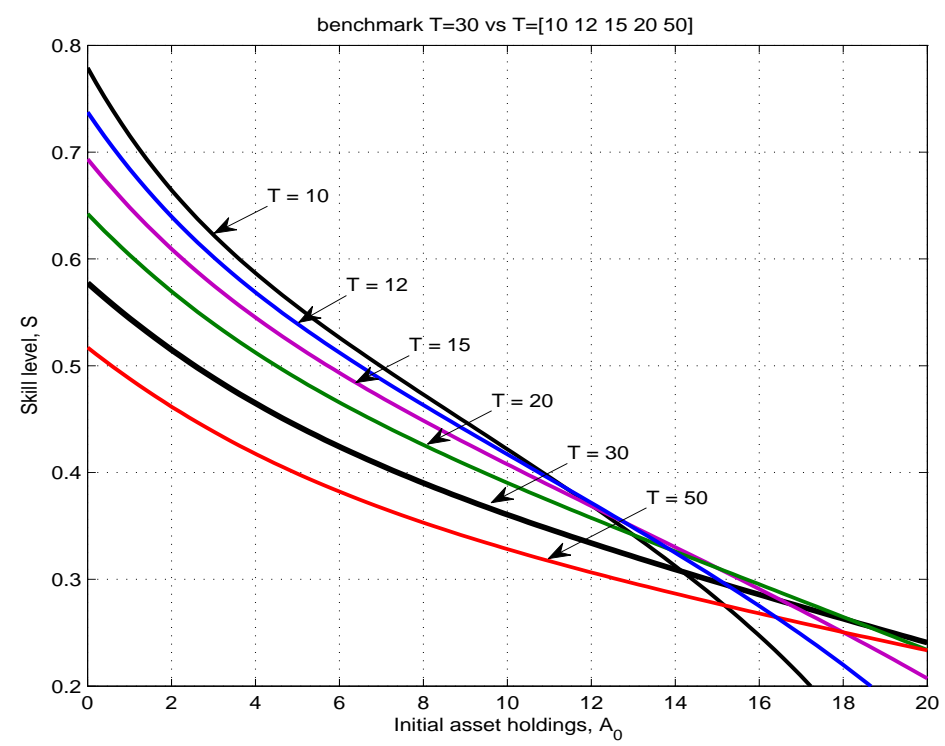

Figure 10: Role of $T$.

For individuals with high initial asset holdings, this remains true, provided they are sufficiently young (i.e., have relatively large values of T). If we consider older asylum seekers, however, such as those with a time horizon of only 10, 12, and 15 years, we observe in Figure 10 that the relationship is reversed. This reversal stems from the assumption that consumption in the refugee camp is fixed at $\bar{c}^{21}$ Fixing consumption at $\bar{c}$ for a wealthy individual who chooses the $\mathrm{R}$ option rules out the possibility of

\footnotetext{
${ }^{21}$ In reality, wealthier individuals in the refugee camp do tend to enjoy a higher consumption rate when compared with their relatively poorer camp-mates. An unusually strong consumption pattern, however, can jeopardize the prospects for resettlement if it gives the impression that the asylum seeker is able to manage well on his own with the resources at his disposal. This consideration is one key element that serves to constrain consumption in the camp of the relatively wealthy applicants for resettlement. Thus the assumption that their consumption is at $\bar{c}$ is not as strong as might appear at first sight.
} 
consumption smoothing until departure from the camp at time $\tau$. In consequence, a reduction in an already short time horizon of such an individual lowers $E_{0}\left(V^{R}\right)$ by more than it does $E_{0}\left(V^{U}\right)$. To keep him indifferent between the two options, $\mathrm{S}$ must be lower for a smaller $\mathrm{T}$. The $\mathrm{T}=10$ schedule is therefore below the $\mathrm{T}=12$ locus for high values of initial asset holdings, as can be seen in the lower right hand corner of Figure 12.

\subsection{A Brief Note on Access to Credit}

Our analysis to this point is based on the assumption that asylum seekers have access to credit from the family network to cover the cost of undocumented migration (if the $\mathrm{U}$ option is chosen) and the cost of seeking resettlement (if $\mathrm{R}$ is chosen). In reality, the vast majority of asylum seekers do not have adequate access to credit that would allow them to choose freely between the two options.

When credit is not available, we have a special case of the model described in the previous sections. To determine who chooses what option, we need to compare $K$ and $A_{0}$. If an individual's asset holdings are greater than $K$, then all of the preceding analysis applies, bearing in mind that the relevant parts of Figures 1 and 5-10 are for values of $A_{0}>K$. In that case, lack of credit for the purpose of financing migration makes no difference because there is no need for it. Alternatively, if $K>A_{0}>K^{R}$, the $\mathrm{U}$ option is unaffordable and the $\mathrm{R}$ option offers the only possibility of migrating to an advanced country, regardless of the remaining parameters. Finally, if $A_{0}<K^{R}$, there is no possibility of even seeking resettlement. 


\section{Conclusions}

Whether asylum seekers attempt to reach their ultimate destination with the aid of human smugglers or try to get to an advanced country by applying for resettlement at a refugee facility close to the conflict zone, is shown to be a function of their individual characteristics and the environment they face at home, abroad, and along the way. In the current policy setting, those who are relatively young, skilled, posses liquid assets, and have access to credit are found to have stronger incentives to choose the undocumented migration option and greater capacity to bear the risk of failure. Although data that would enable us to test the predictions of the model is not readily available, two studies on resettled refugees and asylum seekers in Sweden provide some preliminary evidence on selection that is supportive of the model's key predictions. Bevelander (2009) and Bevelander and Pendakur (2009) find that refugees who sought asylum at the border and who subsequently obtained a residence permit are, on average, more educated and have higher employment rates than both resettled refugees and family-reunification immigrants, controlling for their country of origin and other personal characteristics. Moreover, those who sought asylum at the border are more likely to engage in self-employment activities in comparison with members of the two other categories of immigrants. This latter finding suggests that their initial asset holdings are also likely to have been higher on arrival, as we would expect to be the case on the basis of our model.

Another contribution of the present study is to shead light on the role of a wide range of policies that affect the relative attractiveness of resettlement vs. undocumented migration from the perspective of an asylum seeker. Starting from an equilibrium in which an individual is indifferent between the two options, the deterrent effect of a one-percent decrease in the probability of success in reaching an advanced country as an undocumented migrant is equivalent, for the benchmark values of the model's parameters, to a $6.6 \%$ increase in the wage penalty, a $9 \%$ increase in the waiting period for legalizing 
residence status in the host country, or a $5 \%$ jump in the cost of migration. Increasing the amount of support provided to refugees in the camps or reducing the waiting period required for obtaining a resettlement decision also serves as a deterrent to undocumented migration. A $10 \%$ increase in the daily support ration or a $7.3 \%$ reduction in the waiting period both have the same impact on the relative attractiveness of resettlement vs. undocumented migration as a $1 \%$ reduction in the probability of gaining entry into an advanced country without proper documentation. While these findings have useful policy implications, it is obvious that there is still an enormous task ahead of us if we are to gain better understanding of asylum seeking behavior. The present contribution is, hopefully, a step in that direction. 


\section{References}

Bevelander, P., 2009, "In the Picture - Resettled Refugees in Sweden," in P. Bevelander et al, eds. Resettled and Included? (Malmo, Sweden: Malmo University).

Bevelander, P. and R. Pendakur, 2009, "The Employment Attachment of Resettled Refugees, Refugees and Family Reunion Migrants in Sweden," in P. Bevelander et al, eds. Resettled and Included? (Malmo, Sweden: Malmo University).

Clemens, M.A., C.E. Montenegro, and L. Pritchett, 2009, "The Place Premium: Wage Differences for Identical Workers Across US Border," RWP09-004, Harvard Kennedy School.

Crisp, J. and D. Dessalegne, 2002, "Refugee Protection and Migration Management: The Challenge for UNHCR," working paper, New Issues in Refugee Research, no. 64, UNHCR.

Czaika, M., 2009, "The Political Economy of Refugee Migration," Journal of Economics and Statistics, vol. 229: 803-821.

DeVoretz, D., S. Pivnenko and M. Beiser, 2004, "The Economic Experience of Refugees in Canada," IZA Discussion Paper No. 1088, IZA, Bonn.

Djajić, S., 2010, "Investment Opportunities in the Source Country and Temporary Migration," Canadian Journal of Economics, vol. 43: 663-682.

Djajić, S., and A. Vinogradova. 2013. "Undocumented Migrants in Debt," Labour Economics, vol. 21: 15-24.

Djajić, S. and A. Vinogradova, 2014, "Liquidity-Constrained Migrants," Journal of International Economics. 
Engel, S. and A.M. Ibanez, 2007, Displacement Due to Violence in Colombia: A Household Level Analysis," Economic Development and Cultural Change, vol. 55: 335365.

Facchini, G., O. Lorz and G. Willmann, 2006, "Asylum Seekers in Europe: The Warm Glow of a Hot Potato," Journal of Population Economics, vol. 19: 411-430.

Friebel, G., and S. Guriev, 2006, "Smuggling Humans: A Theory of Debt-Financed Migration," Journal of the European Economic Association, vol. 4: 1085-1111.

Gathmann, C., 2008, "Effects of Enforcement on Illegal Markets: Evidence from Migrant Smuggling Along the Southwestern Border," Journal of Public Economics, vol. 92: 1926-1941.

Gibney, M. and R. Hansen, 2002, "Asylum Policy in the West: Past Trends, Future Possibilities." Paper presented at the WIDER Conference on Poverty, International Migration and Asylum, September 27-28, 2002, Helsinki, Finland.

Grabska, K., 2006, "Marginalization in the Urban Spaces of the Global South: Urban Refugees in Cairo", Journal of Refugee Studies, vol. 19: 287-307.

Hatton, T.J., 2004, "Seeking Asylum in Europe," Economic Policy, vol. 38: 5-62.

Hatton, T.J., 2009, "The Rise and Fall of Asylum," Economic Journal, vol. 119: F183-F213.

Holzer, T., G. Schneider, and T. Widmer, 2000, "The Impact of Legislative Deterrence Measures on the Number of Asylum Seekers in Switzerland," International Migration Review, vol. 34: 1182-216.

IOM, 2010, World Migration Report, International Organization for Migration, Geneva. 
IRIN, 2005, "Africa: A Home Far Away from Home: Third Country Resettlement of Refugees," available at http://www.irinnews.org/InDepthMain.aspx?InDepthId=16\&ReportId=62483

IRIN, 2010, "Syria: The Road to Third Country Resettlement for Iraqi Refugees," available at http://www.irinnews.org/report.aspx?ReportId $=88271$

Jacobsen, K., 2005, The Economic Life of Refugees (Bloomfield, CT: Kumarian Press).

Jansen, B.J., 2008, "Between Vulnerability and Assertiveness: Negotiating Resettlement in Kakuma Refugee Camp, Kenya," African Affairs, vol. 1/0: 1-19.

Kossoudji, S. and D. Cobb-Clark, 2002, "Coming Out of the Shadows: Learning about Legal Status and Wages from the Legalized Population," Journal of Labor Economics, vol. 20: 598-628.

Landau, L., and K. Jacobsen, 2004, "Refugees in the New Johannesburg," Forced Migration Review, vol. 19: 44-46.

Leise, E., 2007, "Germany to Regularize "Tolerated" Asylum Seekers," Migration Information Source, Migration Policy Institute, Washington, D.C., available at http://www.migrationinform

Monheim, J., 2008, "Human Trafficking and the Effectiveness of Asylum Policies," German Working Papers in Law and Economics No. 2008-1-1221, Berkeley Electronic Press.

Morrison, J., and B. Crosland, 2001, "The Trafficking and Smuggling of Refugees: The End Game in European Asylum Policy," WP No. 39, New Issues in Refugee Research, UNHCR, Geneva.

Munshi, K., 2003, "Networks in the Modern Economy: Mexican Migrants in the U.S. Labor Market," Quarterly Journal of Economics, vol. 118, no. 2: 549-99. 
Neumayer, E., 2004, "Asylum Destination Choice: What Makes some West European Countries more Attractive than Others?" European Union Politics, vol. 5: 155-80.

Neumayer, E., 2005, "Asylum Recognition Rates in Western Europe: The Determinants, Variation, and Lack of Convergence," Journal of Conflict Resolution, vol. 49: $43-66$.

North, D.S. and M. Houston, 1976, "The Characteristics and Role of Illegal Aliens in the United States Labor Market: An Exploratory Study," mimeo, Linton and Co., Washington, D.C.

Oxfam, 2005, Foreign Territory: Internationalization of EU Asylum Policy (Oxford: Oxfam Publishing).

Petros, M. 2005. "The Cost of Human Smuggling and Trafficking," Global Migration Perspective, Report no. 31, Global Commission on International Migration.

Rivera-Batiz, F.L., 1999, "Undocumented Workers in the Labor Market: An Analysis of the Earnings of Legal and Illegal Mexican Immigrants in the United States," Journal of Population Economics, vol. 12: 91-116.

Rivera-Batiz, F.L., 2000, "Underground on American Soil: Undocumented Workers and U.S. Immigration Policy," Journal of International Affairs, vol. 53: 485-501.

Schaeffer, P., 2009, "Refugees: On the Economics of Political Migration," International Migration, vol. 48: 1-22.

UNHCR, 2009, "2008 Global Trends: Refugees, Asylum-Seekers, Returnees, Internally Displaced and Stateless Persons," report prepared by the Field Information and Coordination Support Section, UNHCR, Geneva. Available at http://www.unhcr.org/4a375c426.html 
Tamura, Y., 2010, "Migrant Smuggling," Journal of Public Economics, vol. 94: 540548.

Tamura, Y. 2013. "Migrant Smuggling when Exploitation is Private Information," forthcoming, Canadian Journal of Economics.

Thielemann, E.R., 2005, "Symbolic Politics or Effective Burden Sharing? Redistribution, Side-payments and the European Refugee Fund," Journal of Common Market Studies, vol. 43: 807-24.

Van Hear, N., 2010, "In the Mix: The Growing Salience of Mixed Migration as an Analytical and Policy Concept," paper presented at the Conference on The Concept of Mixed Migration, Geneva, 8-9 April, 2010.

Vink, M. and F. Meijerink, 2003, "Asylum Applications and Recognition Rates in EU Member States 1982-2001: A Quantitative Analysis," Journal of Refugee Studies, vol. 16: $297-315$.

Wasem, R.E., 2002, "Immigration Legislation and Status Adjustment Legislation," Congressional Research Service Report for Congress, RL30780, The Library of Congress, Washington D.C.

Wasem, R.E., 2006, "U.S. Immigration Policy on Asylum Seekers," Congressional Research Service Report for Congress, RL32621, The Library of Congress, Washington D.C. 


\section{A Appendix}

\section{A.1 Role of $\Omega$}

The purpose of this appendix is to establish that the expected utility of an agent who chooses the $\mathrm{R}$ option is more responsive to a change in $\Omega$ than the expected utility of a migrant who choose $\mathrm{U}$ for all realistic values of $\alpha$ and $\beta$. I consider all values of $S \in[0.2,1]$ and hold other parameters at their benchmark levels, while setting $\Omega$ at its equilibrium value. An equilibrium is defined as the situation where $E_{0}\left(V^{R}\right)=E_{0}\left(V^{U}\right)$. In other words, I want to show that $\frac{\partial E_{0}\left(V^{R}\right)}{\partial \Omega}>\frac{\partial E_{0}\left(V^{U}\right)}{\partial \Omega}$ for all $S$ and $\Omega$ when $\alpha$ and $\beta$ take on plausible values.

The expressions for the slopes are as follows

$$
\begin{gathered}
\frac{\partial E_{0}\left(V^{R}\right)}{\partial \Omega}=(1-\beta) \frac{e^{-r \tau}-e^{-r T}}{r(1-\theta)}\left(\left(c^{R *}\right)^{1-\theta}-\left(c^{R}\right)^{1-\theta}\right), \\
\frac{\partial E_{0}\left(V^{U}\right)}{\partial \Omega}=\pi\left(c^{*}\right)^{-\theta} w^{*} S \sigma \phi_{0}(1-\alpha) e^{-r \phi(S, \Omega)} .
\end{gathered}
$$

Figure 11 below plots the difference of the slopes, $\frac{\partial E_{0}\left(V^{R}\right)}{\partial \Omega}-\frac{\partial E_{0}\left(V^{U}\right)}{\partial \Omega}$, as a function of $\alpha$ and $\beta$ for $S=0.5$ and $\Omega$ at its equilibrium level. ${ }^{22}$ Only for combinations of extremely high values of $\beta>0.95$ (corresponding to a policy where a positive decision on a resettlement application depends almost entirely on an applicant's skill level rather than on the level of security risk) and $\alpha<0.2$ (corresponding to a policy according to which quick access to permanent residence for an undocumented migrant depends very little on $\mathrm{S}$ and mostly on $\Omega$ ) is the difference between the slopes of $E_{0}\left(V^{R}\right)$ and $E_{0}\left(V^{U}\right)$ negative. The same analysis was performed for all $S \in[0.2,1]$, and it can be shown that $\frac{\partial E_{0}\left(V^{R}\right)}{\partial \Omega}-\frac{\partial E_{0}\left(V^{U}\right)}{\partial \Omega}$ is positive $\forall \alpha, \beta$ if $0.8<S<0.4$, while for the remaining values of $S$ the difference in the slopes is negative only for $\beta>0.8$ and small values of $\alpha$ (i.e., very

\footnotetext{
${ }^{22}$ Note that the equilibrium $\Omega$ varies with $\alpha$ and $\beta$.
} 
similar to what is shown in Figure 11, which corresponds to $S=0.5$ ).

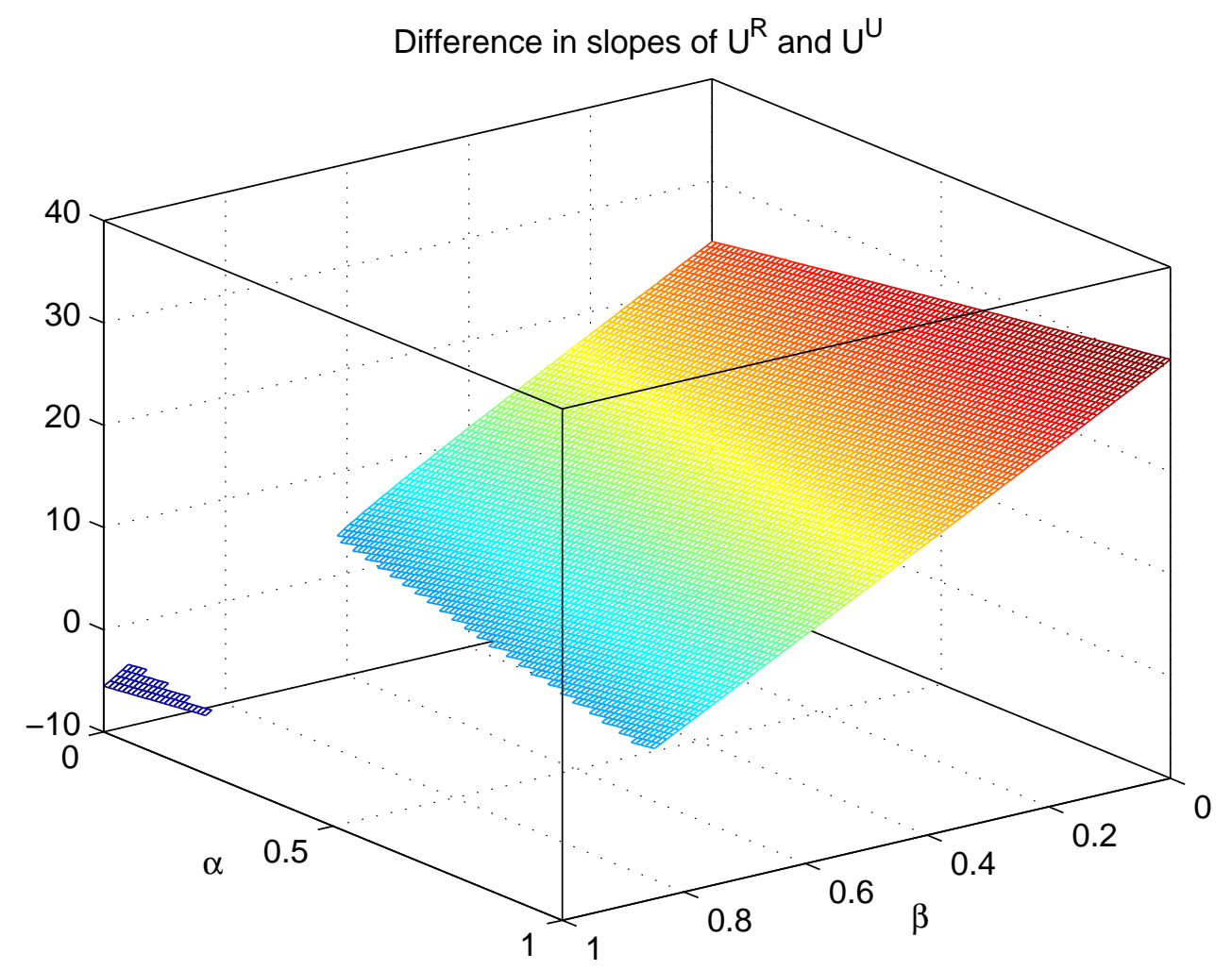

Figure 11: Difference in slopes.

\section{A.2 Role of $S$}

The expected utility of an agent who chooses $\mathrm{R}$ is less responsive to a change in $S$ than the expected utility of an agent who chooses $\mathrm{U}$ for all values of $\alpha, \beta$, and $\Omega$, holding other parameters fixed, while setting $S$ at its equilibrium value. That is, it can be shown that $\frac{\partial E_{0}\left(V^{R}\right)}{\partial S}-\frac{\partial E_{0}\left(V^{U}\right)}{\partial S}<0 \forall \alpha, \beta$ and all equilibrium combinations of $S$ and $\Omega$ such that $E_{0}\left(V^{R}\right)=E_{0}\left(V^{U}\right)$. 
The expressions for the slopes are as follows

$$
\begin{gathered}
\frac{\partial E_{0}\left(V^{R}\right)}{\partial S}=\frac{e^{-r \tau}-e^{-r T}}{r}\left[\beta \frac{\left(c^{R *}\right)^{1-\theta}-\left(c^{R}\right)^{1-\theta}}{1-\theta}+\pi^{R} w^{*}\left(c^{R *}\right)^{-\theta}-\left(1-\pi^{R}\right) w\left(c^{R}\right)^{-\theta}\right], \\
\frac{\partial E_{0}\left(V^{U}\right)}{\partial S}=\frac{1}{r}\left[\pi\left(c^{*}\right)^{-\theta} w^{*}\left[1-\sigma-e^{-r T}+\sigma e^{-r \phi}\left(1+\operatorname{Sr} \phi_{0} \alpha\right)\right]+(1-\pi)\left(1-e^{-r T}\right) c^{-\theta} w\right] .
\end{gathered}
$$

Figure 12 below plots the difference of the slopes, $\frac{\partial E_{0}\left(V^{R}\right)}{\partial S}-\frac{\partial E_{0}\left(V^{U}\right)}{\partial S}$ as a function of $\alpha$ and $\beta$ for $\Omega=0.5$ with $S$ taking on its corresponding equilibrium value.

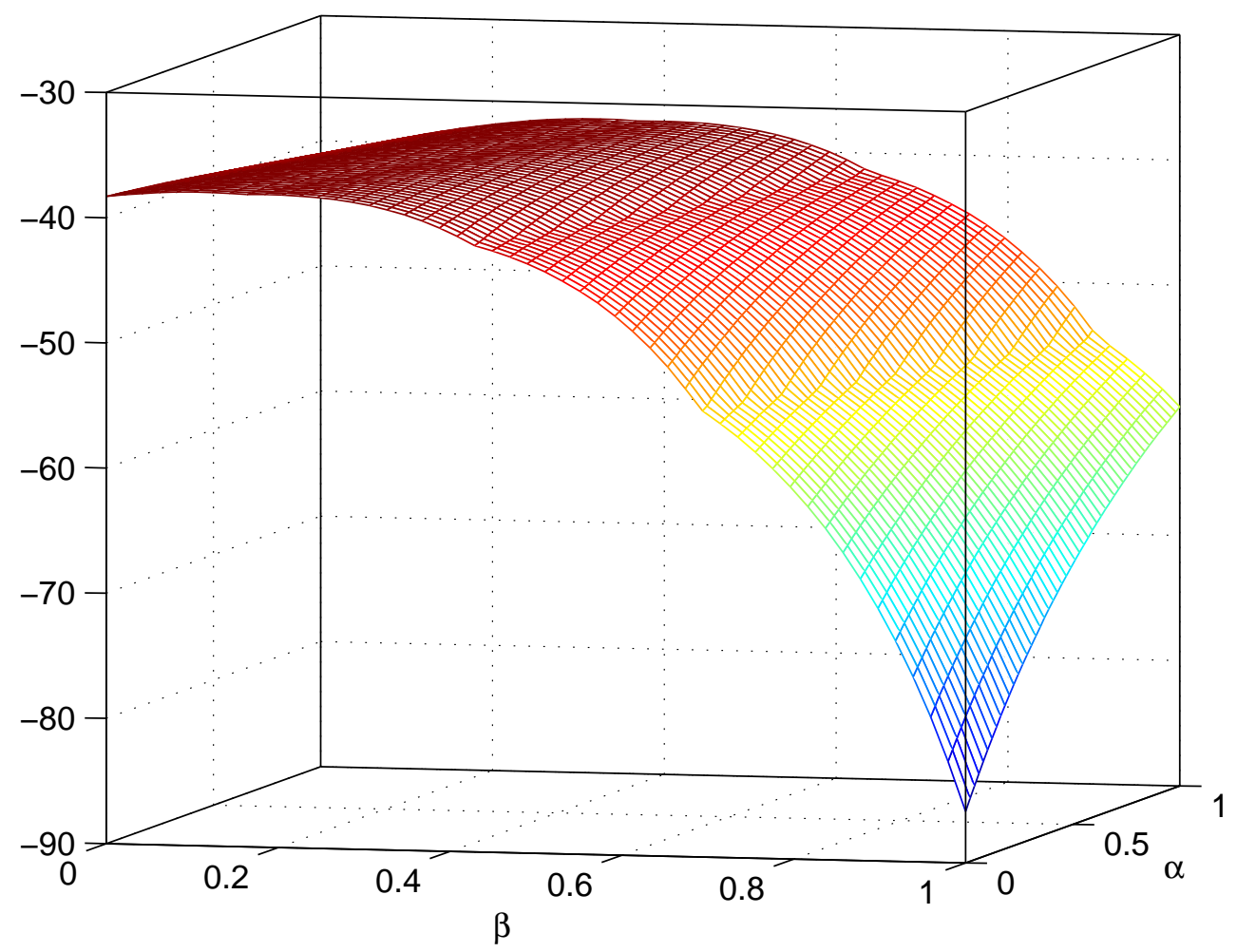

Figure 12: Difference in slopes.

The difference in the slopes is shown to be always negative. Moreover, this result continues to hold for all values of $S \in[0.2,1]$ and $\Omega \in[0,1]$, such that $E_{0}\left(V^{R}\right)=E_{0}\left(V^{U}\right)$. 


\section{A.3 Role of $w^{*}$}

For realistic values of the model's parameters, the expected utility of $\mathrm{R}$ is always less responsive to a change in $w^{*}$ than the expected utility of $\mathrm{U}$. The expressions for the slopes are as follows

$$
\begin{gathered}
\frac{\partial E_{0}\left(V^{R}\right)}{\partial w^{*}}=\pi^{R}\left(c^{R *}\right)^{-\theta}\left(e^{-r \tau}-e^{-r T}\right), \\
\frac{\partial E_{0}\left(V^{U}\right)}{\partial w^{*}}=\pi\left(c^{*}\right)^{-\theta}\left[1+\sigma\left(e^{-r \phi}-1\right)-e^{-r T}\right] .
\end{gathered}
$$

Since $\pi>\pi^{R}$ and $\left(c^{*}\right)^{-\theta}>\left(c^{R *}\right)^{-\theta}$, a visual comparison of the above expressions for the slopes suggests that $\frac{\partial E_{0}\left(V^{R}\right)}{\partial w^{*}}<\frac{\partial E_{0}\left(V^{U}\right)}{\partial w^{*}}$. To verify this, calculations were first made for all values of $\alpha$ and $\beta$, while holding $\Omega$ and other parameters at their benchmark values and setting $S$ such that $E_{0}\left(V^{R}\right)=E_{0}\left(V^{U}\right)$. Further simulations confirm that $\frac{\partial E_{0}\left(V^{R}\right)}{\partial w^{*}}<\frac{\partial E_{0}\left(V^{U}\right)}{\partial w^{*}}$ not only for the benchmark case but for all values of $\Omega \in[0,1]$ and what in light of Clemens et al (2009) may be considered empirically relevant values of $w^{*}$ in the range between 3 and 15 . Moreover, while it may appear that if $\phi_{0}$ and $\sigma$ are sufficiently large and $\tau$ sufficiently small, that $\frac{\partial E_{0}\left(V^{R}\right)}{\partial w^{*}}$ can exceed $\frac{\partial E_{0}\left(V^{U}\right)}{\partial w^{*}}$ at a point where $E_{0}\left(V^{R}\right)=E_{0}\left(V^{U}\right)$, this is not the case. If one raises $\sigma$ to $0.9, \phi_{0}$ to 30 and lowers $\tau$ to 1 , which stacks the cards as much as realistically possible in favor of increasing the responsiveness of $E_{0}\left(V^{R}\right)$ relative to that of $E_{0}\left(V^{U}\right)$ with respect to $w^{*}$, it is still the case that $\frac{\partial E_{0}\left(V^{R}\right)}{\partial w^{*}}<\frac{\partial E_{0}\left(V^{U}\right)}{\partial w^{*}}$ for the limited range of the other parameters of the model such that $E_{0}\left(V^{R}\right)=E_{0}\left(V^{U}\right)$. 